\title{
Endophytes from Wild Rubber Trees as Antagonists of the Pathogen Corynespora cassiicola
}

\author{
Valérie Pujade-Renaud,1,2,3,4,† Marine Déon, $1,2,3,4$ Romina Gazis, 5 Sébastien Ribeiro, 1,2,3,4 Florence Dessailly,3,4 \\ Françoise Granet, ${ }^{6}$ and Priscila Chaverri, 7,8 \\ ${ }^{1}$ Université Clermont Auvergne, Institut National de la Recherche Agronomique, UMR PIAF, Clermont-Ferrand, France \\ ${ }^{2}$ CIRAD, UMR AGAP, F-63000 Clermont-Ferrand, France \\ ${ }^{3}$ CIRAD, UMR AGAP, F-34398 Montpellier, France \\ ${ }^{4}$ AGAP, Université Montpellier, CIRAD, INRA, Montpellier SupAgro, Montpellier, France \\ 5 Tropical Research and Education Center, Department of Plant Pathology, University of Florida, Homestead, FL 33031, U.S.A. \\ ${ }^{6}$ Manufacture Française des Pneumatiques MICHELIN, Place des Carmes-Déchaux, Clermont-Ferrand Cedex, France \\ ${ }^{7}$ Department of Plant Science and Landscape Architecture, 2112 Plant Sciences Building, University of Maryland, College Park, MD 20742, \\ U.S.A. \\ ${ }^{8}$ Escuela de Biología and Centro de Investigación en Productos Naturales, Universidad de Costa Rica, San Pedro, San José, Costa Rica \\ Accepted for publication 7 July 2019.
}

\begin{abstract}
The Corynespora leaf fall disease of rubber trees, caused by the necrotrophic fungus Corynespora cassiicola, is responsible for important yield losses in Asian and African plantations, whereas its impact is negligible in South America. The objective of this study was to identify potential antagonists of $C$. cassiicola among fungal endophytes (i.e., Pestalotiopsis, Colletotrichum, and Trichoderma spp.) isolated from wild and cultivated rubber trees distributed in the Peruvian Amazon. We first tested the endophytes in dual in vitro confrontation assays against a virulent $C$. cassiicola isolate (CCP) obtained from diseased rubber trees in the Philippines. All Trichoderma isolates overran the CCP colony, suggesting some antagonistic mechanism, while species from the other

from a wild Hevea guianensis specimen and identified as Trichoderma koningiopsis, showed significant antibiosis capacity. We demonstrated that LA279 was also able to endophytically colonize the cultivated rubber tree species (H. brasiliensis). Under controlled laboratory conditions, rubber plants were inoculated with three Trichoderma strains, including LA279, in combination with the pathogenic CCP. Results showed that 1 week preinoculation with the endophytes differentially reduced CCP mycelial development and symptoms. In conclusion, this study suggests that T. koningiopsis isolate LA279 — and derivate compounds—could be a promising candidate for the biological control of the important rubber tree pathogen C. cassiicola.
\end{abstract} genera behaved as mutual antagonists. Trichoderma isolates were then tested through antibiosis assays for their capacity to produce growthinhibiting molecules. One isolate (LA279), recovered as an endophyte
Keywords: biological control, disease control and pest management, mycology
Corynespora cassiicola (Berk. \& M. A. Curtis) C. T. Wei is an ascomycete that causes disease in a wide range of plants from tropical and subtropical countries (Farr and Rossman 2016). This phytopathogen can also infect, on rare occasions, immunocompromised humans (Mahgoub 1969; Xie et al. 2018). In plants, it is mostly known as a necrotrophic pathogen but has also been reported as an endophyte and saprophyte (Déon et al. 2012b; Dixon et al. 2009). In the rubber tree (Hevea brasiliensis Müll. Arg), C. cassiicola causes Corynespora leaf fall (CLF) disease, which is responsible for important yield losses in Asia and Africa, where most natural rubber is produced. In South America, no CLF outbreak was reported, although the presence of $C$. cassiicola infecting rubber plants was occasionally mentioned in Brazil (Gasparotto et al. 1988). C. cassiicola has also been detected as an endophyte in asymptomatic rubber tree leaves collected in a

†Corresponding author: V. Pujade-Renaud; Valerie.PUJADE-RENAUD@cirad.fr

Funding: This project was funded by National Science Foundation grant DEB925672 to P. Chaverri and DEB-1019972 to P. Chaverri, V. Pujade-Renaud, A. Goes-Neto, and K. Wurdack.

*The $\boldsymbol{e}$-Xtra logo stands for "electronic extra" and indicates that one supplementary figure is published online.

The author(s) declare no conflict of interest.

(c) 2019 The American Phytopathological Society
Brazilian rubber plantation (Déon et al. 2012b). Many studies have described the large genetic diversity among C. cassiicola isolates, with multiple evidence of host specialization (Déon et al. 2014; Dixon et al. 2009; Hieu et al. 2014; Qi et al. 2011; Shimomoto et al. 2011; Sumabat et al. 2018; Wu et al. 2018b,a).

Control of CLF has relied mostly on chemical treatments and improved genetic resistance. However, other alternatives such as biological control should be considered, due to the important cost and the ecological damage associated with the use of fungicides (Heimpel et al. 2013). There are few published studies on biological control agents or strategies for fighting C. cassiicola. Several soilborne or endophytic bacterial species have been found to inhibit-in vitro-the mycelial growth of C. cassiicola (Kadyan et al. 2013; Mathiyazhagan et al. 2004) and of an unspecified Corynespora sp. (Barreto et al. 2008). In addition, in planta tests in cucumber showed that root colonization by Pseudomonas chlororaphis, a nonpathogenic bacterium isolated from the rhizosphere of wheat, induced systemic resistance, protecting the plant against C. cassiicola (Kim et al. 2004; Silva et al. 2004). Recently, it was reported that culture filtrates of the yeast Hanseniaspora opuntiae can protect soybean plants against $C$. cassiicola (Ferreira-Saab et al. 2018). However, the potential of fungal agents for the biocontrol of C. cassiicola has not yet been explored.

Classical biocontrol aims to restore ecological balance and reduce pathogen levels by introducing coevolved natural enemies or biocontrol agents. These agents are selected for their high specificity and their presence in the "center of origin" or native 
habitat of their host (Evans 2008). For example, several species belonging to the genus Trichoderma, isolated as endophytes of wild Theobroma spp. (cacao and relatives), have shown antagonistic properties against cacao pathogens (Bailey et al. 2008; Evans 2002; Hanada et al. 2008). Similarly, endophytes with antagonistic properties against $C$. cassiicola are expected to be found in the Amazon basin, center of origin of Hevea, where important areas with disease-free rubber trees are located (Evans 2002). The ubiquity of endophytic fungi among and within plants, and the premise that endophytic fungi have been associated with plants since they first colonized land, suggests that plants and endophytes likely have an intimate relationship (Berbee 2001; Heckman et al. 2001). The role that endophytes play in plants may range from mutualistic to pathogenic. Increasing evidence suggests a mutualistic relationship, in which some fungal endophytes increase resistance to plant pathogens and produce antifungal and antiherbivory compounds (Rodriguez et al. 2009). Gazis and Chaverri (2015) presented preliminary data on the biocontrol of Colletotrichum acutatum (strain AF1 from Nigeria) and C. gloeosporioides (strain Colle-Mex from Mexico) using 70 different strains of endophytic Trichoderma spp. isolated from wild and cultivated Hevea trees distributed in the Peruvian Amazon. All tested Trichoderma strains inhibited the growth of two Colletotrichum spp. but strains isolated from wild trees had the highest inhibition effect. In this context, the biocontrol potential among endophytes of wild rubber trees from the Amazon basin seems promising.
The objective of this study was to identify fungal isolates, from wild and cultivated rubber trees, antagonistic toward the important rubber tree pathogen Corynespora cassiicola. Fungal endophytes used in the experiments were isolated from rubber trees in countries where $C$. cassiicola is known to occur but no CLF outbreak has been reported. These endophytes were tested against a virulent $C$. cassiicola isolate from the Philippines (CCP) through both direct fungal confrontation tests (dual culture and antibiosis) and in planta assays.

\section{MATERIALS AND METHODS}

Fungal isolates. $\mathrm{CCP}$ is a virulent $C$. cassiicola isolate collected from a rubber plantation in the Philippines. This strain has been characterized (Breton et al. 2000; Déon et al. 2012a) and was chosen as reference for the $C$. cassiicola species as part of the "1,000 fungal genomes" project (Lopez et al. 2018).

Fungal endophytes were isolated from living leaf and sapwood (vascular phloem plus cambium) tissue of Hevea spp. trees (Hevea brasiliensis and H. guianensis Aubl.) from Peru. Trees were mostly distributed in undisturbed natural forests but a few trees also were sampled from a plantation located in the town of Iberia (Table 1), as described previously (Gazis and Chaverri 2015). Endophyte isolation was performed immediately after sampling, as described by Gazis and Chaverri (2010). Briefly, three segments of approximately 3 by $3 \mathrm{~mm}$ from each leaflet were surface sterilized through sequential immersion in $2 \%$ ( $\mathrm{vol} / \mathrm{vol})$ sodium hypochlorite

TABLE 1. Endophyte isolates used in this study

\begin{tabular}{|c|c|c|c|c|c|c|}
\hline \multicolumn{4}{|c|}{ Endophyte } & \multicolumn{3}{|c|}{ Host } \\
\hline Name & Species & Country & Area & Host species & $\mathrm{W} / \mathrm{P}^{\mathrm{a}}$ & Tissue $^{\mathrm{b}}$ \\
\hline IQ41 & Colletotrichum cf. gloeosporioides & Peru & Iquitos & Hevea brasiliensis & $\mathrm{W}$ & $\mathrm{L}$ \\
\hline IQ60 & C. cf. gloeosporioides & Peru & Iquitos & H. brasiliensis & W & $\mathrm{L}$ \\
\hline IQ95 & C. cf. gloeosporioides & Peru & Iquitos & H. brasiliensis & W & $\mathrm{L}$ \\
\hline IQ165 & C. cf. gloeosporioides & Peru & Iquitos & H. brasiliensis & $\mathrm{W}$ & $\mathrm{L}$ \\
\hline IQ170 & C. cf. gloeosporioides & Peru & Iquitos & H. brasiliensis & $\mathrm{W}$ & $\mathrm{L}$ \\
\hline IB28 & Pestalotiopsis cf. palmarum & Peru & Iberia & H. brasiliensis & $\mathrm{P}$ & SW \\
\hline IB142 & $P$. cf. palmarum & Peru & Iberia & H. brasiliensis & $\mathrm{P}$ & SW \\
\hline IB212 & P. cf. palmarum & Peru & Iberia & H. brasiliensis & $\mathrm{P}$ & SW \\
\hline IB230 & P. cf. palmarum & Peru & Iberia & H. brasiliensis & $\mathrm{P}$ & SW \\
\hline LA67 & P. cf. palmarum & Peru & Los Amigos & H. guianensis & W & SW \\
\hline LA69 & P. cf. palmarum & Peru & Los Amigos & H. guianensis & W & SW \\
\hline PP18 & P. cf. palmarum & Peru & Tambopata & H. brasiliensis & W & $\mathrm{L}$ \\
\hline PP28 & P. cf. palmarum & Peru & Tambopata & H. brasiliensis & $\mathrm{W}$ & $\mathrm{L}$ \\
\hline PP105 & P. cf. palmarum & Peru & Tambopata & H. brasiliensis & $\mathrm{W}$ & $\mathrm{L}$ \\
\hline PP109 & P. cf. palmarum & Peru & Tambopata & H. brasiliensis & $\mathrm{W}$ & $\mathrm{L}$ \\
\hline PP116 & P. cf. palmarum & Peru & Tambopata & H. brasiliensis & $\mathrm{W}$ & $\mathrm{L}$ \\
\hline PP119 & P. cf. palmarum & Peru & Tambopata & H. brasiliensis & $\mathrm{W}$ & $\mathrm{L}$ \\
\hline IB44 & Trichoderma cf. atroviride & Peru & Iberia & H. brasiliensis & $\mathrm{P}$ & $\mathrm{L}$ \\
\hline IB49A & T. amazonicum & Peru & Iberia & H. brasiliensis & $\mathrm{P}$ & SW \\
\hline IQ211 & T. cf. strigosellum & Peru & Iquitos & H. brasiliensis & W & SW \\
\hline IQ213 & T. cf. strigosellum & Peru & Iquitos & H. brasiliensis & $\mathrm{W}$ & SW \\
\hline IQ250 & T. lentiforme & Peru & Iquitos & H. brasiliensis & W & SW \\
\hline LA10 & T. endophyticum & Peru & Los Amigos & H. guianensis & $\mathrm{W}$ & SW \\
\hline LA11 & T. amazonicum & Peru & Los Amigos & H. guianensis & $\mathrm{W}$ & SW \\
\hline LA35 & T. cf. harzianum (complex) & Peru & Los Amigos & H. guianensis & $\mathrm{W}$ & SW \\
\hline LA278 & T. koningiopsis & Peru & Los Amigos & H. guianensis & W & SW \\
\hline LA279 & T. koningiopsis & Peru & Los Amigos & H. guianensis & $\mathrm{W}$ & SW \\
\hline MS122 & T. cf. harzianum (complex) & Peru & Madre Selva & H. brasiliensis & $\mathrm{W}$ & SW \\
\hline MS437 & T. endophyticum & Peru & Madre Selva & H. brasiliensis & W & SW \\
\hline MS440 & T. endophyticum & Peru & Madre Selva & H. brasiliensis & $\mathrm{W}$ & SW \\
\hline $\mathrm{T} 2$ & T. lentiforme & Peru & Tambopata & H. brasiliensis & $\mathrm{W}$ & SW \\
\hline $\mathrm{T} 3$ & T. endophyticum & Peru & Tambopata & H. brasiliensis & $\mathrm{W}$ & SW \\
\hline $\mathrm{T} 7$ & T. endophyticum & Peru & Tambopata & H. brasiliensis & $\mathrm{W}$ & SW \\
\hline $\mathrm{H} 10$ & T. lentiforme & Peru & Tambopata & H. brasiliensis & $\mathrm{W}$ & SW \\
\hline PP24 & T. endophyticum & Peru & Tambopata & H. brasiliensis & W & SW \\
\hline PP89 & T. endophyticum & Peru & Tambopata & H. brasiliensis & W & $\mathrm{L}$ \\
\hline PP107 & T. cf. harzianum (complex) & Peru & Tambopata & H. brasiliensis & $\mathrm{W}$ & $\mathrm{L}$ \\
\hline PP136 & T. neotropicale & Peru & Tambopata & H. brasiliensis & W & SW \\
\hline
\end{tabular}

${ }^{a} \mathrm{~W}=$ wild and $\mathrm{P}=$ plantation.

${ }^{\mathrm{b}} \mathrm{L}=$ leaf and $\mathrm{SW}=$ sapwood. 
(bleach) solution, 70\% (vol/vol) ethanol, and sterilized water, and placed onto BBL corn meal agar Petri dishes, amended with $2 \%$ dextrose and antibiotics (1\% solution of neomycin-penicillinstreptomycin; Sigma-Aldrich) (CMD+) to eliminate bacterial endophytes. To isolate endophytes from stems, the vascular phloem or cambium tissue was exposed on three areas of the tree and, in each of those areas, three pieces of living tissue of approximately 5 by $2 \mathrm{~mm}$ were excised and transferred immediately to Petri plates containing CMD+. Species identification was performed by sequencing DNA amplicons corresponding to the internal transcribed spacer (ITS) and the large subunit of the nuclear ribosomal DNA, as well as the translation elongation factor $1 \alpha(t e f 1)$ gene, and sequences were deposited in GenBank (Chaverri et al. 2015; Gazis and Chaverri 2010).

Pure cultures were grown in Petri dishes on potato dextrose agar (PDA; Difco) at $26^{\circ} \mathrm{C}$ (day) to $25^{\circ} \mathrm{C}$ (night) in the dark. Mycelial plugs were kept at $-80^{\circ} \mathrm{C}$ in $20 \%$ glycerol for long-term storage. For conidial production, the mycelium initially grown in the dark was exposed to alternate light ( $12 \mathrm{~h}$ of light and $12 \mathrm{~h}$ of darkness) for approximately 1 week. Sterile water $(5 \mathrm{ml})$ was added to the Petri dish and the mycelium was scrapped with a sterile glass pipet. The collected conidial suspension was adjusted to 5,000 conidia $\mathrm{ml}^{-1}$ for inoculation. The percentage of germination was checked by spreading $100 \mu \mathrm{l}$ of the spore suspension on water jellified with agar and recording the number of mycelial colonies after $24 \mathrm{~h}$ of incubation in the dark at $26^{\circ} \mathrm{C}$.

Plant material. $H$. brasiliensis plants used in this study were sterile in vitro plantlets produced by somatic embryogenesis from cultivar PB260, susceptible to $C$. cassiicola isolate CCP, as previously described (Lardet et al. 1999, 2007, 2009). Briefly, the friable embryogenic callus line CI07060 was established from seed integument (maternal tissue) and cryopreserved. After reactivation, callus was subcultured every 2 weeks on a maintenance culture medium (MM) in the dark at $27^{\circ} \mathrm{C}$. Somatic embryos were produced from $1 \mathrm{~g}$ of callus in 250-ml flasks containing $50 \mathrm{ml}$ of semisolid embryogenesis expression medium (MM supplemented with $58.5 \mathrm{mM}$ sucrose, $175.5 \mathrm{mM}$ maltose, $0.44 \mu \mathrm{M}$ benzyl amino purine [BAP], and $0.44 \mu \mathrm{M} 3,4-\mathrm{D}$ dichlorophénoxyacetic acid). Embryo development was carried out in a temporary immersion system (RITA; CIRAD), with a 1-min daily immersion in liquid development medium (DEV; MM containing $234 \mathrm{mM}$ sucrose and $3 \mathrm{mM} \mathrm{CaCl}_{2}$, without growth regulator), for two subcultures of 4 weeks each. Mature embryos were transferred to glass tubes on a semisolid germination medium (DEV3; MM medium supplemented with $1.5 \mathrm{mM} \mathrm{CaCl}_{2}$ solidified with agar at $7 \mathrm{~g} \mathrm{liter}^{-1}$ ). Embryos were incubated under a light intensity of $60 \mu \mathrm{mol} \mathrm{m} \mathrm{m}^{-2} \mathrm{~s}^{-1}$ and a photoperiod $12 \mathrm{~h} /$ day and $12 \mathrm{~h} /$ night, up to their full conversion into plantlets. Plantlets presenting three to six leaflets were selected for direct in planta tests.

Some of the plantlets used in this study (for the validation of endophytism) were initially obtained by somatic embryogenesis, as described above, but subsequently multiplied by in vitro microcutting (Lardet et al. 1998; Montoro et al. 2012). To do so, the plantlet was removed from its tube and cut into two to three pieces, depending on the stem length, under sterile conditions. Most of the roots and leaves were cut off, and each stem piece was transferred to a new tube containing basal medium for hevea culture $(\mathrm{MH})$ with BAP at $0.2 \mathrm{mg}$ liter ${ }^{-1}$ and indol-3-butyric acid (IBA) at $0.05 \mathrm{mg}^{\text {liter }}{ }^{-1}$ for shoot multiplication. Microcutting was repeated every 2 months on $\mathrm{MH}$ medium alternating with or without hormone to promote shoot multiplication and axillary shoot conditioning, respectively.

Dual-culture assays. Thirty-eight endophytes were tested in dual-culture assays against $C$. cassiicola isolate CCP. Mycelial plugs from actively growing cultures of each endophyte and isolate $\mathrm{CCP}$ were placed on PDA in 9-mm-diameter Petri dishes, $6 \mathrm{~cm}$ apart from each other. The CCP plug was placed 3 days before the endophyte plug to compensate for its slower growth compared with most endophyte isolates tested in this study. All dual cultures were performed in triplicate (i.e., each treatment was applied to three replicate plates). Control cultures (nine replicates) were set with C. cassiicola alone, placed at the same position. Plates were incubated in the dark at $26^{\circ} \mathrm{C}$ (day) to $25^{\circ} \mathrm{C}$ (night) for up to 3 weeks to observe the results of the interaction between the endophytes and CCP. The radial growth of the CCP colony was measured at day 7 , when most endophyte colonies had made contact with the CCP colony. The percentage of growth inhibition (GI\%) was calculated as follows: $\mathrm{GI} \%=(1-\mathrm{DC} / \mathrm{CC}) \times 100$, where $\mathrm{DC}$ is the radial growth of CCP in dual culture and CC is the radial growth of CCP in the control culture (mean from nine replicates). Trichoderma isolates overgrowing (and sporulating) on top of the $C$. cassiicola colony were considered putative mycoparasites of CCP. To further explore this hypothesis, small paper disks covered with freshly grown mycelium of each Trichoderma isolate were placed on top of 1week-old CCP mycelial colonies, without direct contact with the culture medium. Conversely, paper disks covered with CCP mycelium were placed on top of the Trichoderma colonies. Plates were incubated in the dark at $26^{\circ} \mathrm{C}$ (day) to $25^{\circ} \mathrm{C}$ (night) for at least 1 week to observe mycelium development out of the paper disks.

Microscopic observations were performed from dual cultures between Trichoderma isolate LA279 and CCP, as well as control plates. Mycelium was collected from 7-day-old cultures in the confrontation zone (where LA279 mycelium had overgrown the $\mathrm{CCP}$ colony) and observed in water under an Axioskop 40 microscope (Zeiss) at $\times 40$ magnification, and photographed with an AxioCam ICc5 camera (Zeiss).

In vitro antibiosis assay. Trichoderma spp. isolates were further studied through in vitro antibiosis assays because of their known and well-documented production of antifungal secondary metabolites (Contreras-Cornejo et al. 2016; Reino et al. 2008). Culture filtrates were prepared by inoculating $100 \mathrm{ml}$ of modified Czapeck culture medium (CZ) (de Lamotte et al. 2007) in 500-ml flasks with five plugs (6 $\mathrm{mm}$ in diameter) of freshly growing mycelium cultures of Trichoderma spp. (21 different strains). CZ is routinely used for optimal production of $C$. cassiicola effectors (Tran et al. 2016). After 10 days at $26^{\circ} \mathrm{C}$ (day) to $25^{\circ} \mathrm{C}$ (night), with alternate light (12 h of light and $12 \mathrm{~h}$ of darkness), the culture medium was filtrate sterilized through successive disposable filter units of decreasing porosity: $0.45 \mu \mathrm{m}$ (once) and $0.22 \mu \mathrm{m}$ (twice). The filtrates were stored at $4^{\circ} \mathrm{C}$ until use. We verified that long-term storage of the sterile filtrate (for at least 1 year) did not modify significantly the antibiosis activity (data not shown). Three biological replicates (three filtrates from three different source plates) were prepared for each fungal strain. Filtrates from a $C$. cassiicola isolate (CCP) and noninoculated $\mathrm{CZ}$ were used as controls.

Each filtrate $(12 \mathrm{ml})$ was mixed with the same volume of melted PDA medium with agar at $30 \mathrm{~g} / \mathrm{liter}$ ), both preheated to $60^{\circ} \mathrm{C}$ using a water bath (to avoid solidification of the agar), and poured into 55mm-diameter Petri dishes. Three plates were prepared for each filtrate (technical replicates). A mycelial plug of CCP was placed at the center of the Petri dish and plates were incubated for 12 days in the dark at 25 to $26^{\circ} \mathrm{C}$. The growth of each colony was scored as the mean of two perpendicular diameters, at 2, 5, 9, and 12 days after inoculation. Statistical differences between filtrates were analyzed using analysis of variance under R software, version 3.2.3 (R Core Team 2015), and tested using the Tukey's honestly significant difference (HSD) test $(P<0.05)$.

In planta tests. To test the antagonism of selected Trichoderma isolates toward the pathogenic isolate CCP in planta, we used sterile Hevea plantlets grown in vitro (see "Plant material" section) rather than plants grown in soil that may contain unwanted endophytes. In vitro plantlets were not soil acclimatized before biocontrol experiments but directly inoculated in their tube. Due to the limited availability of in vitro plantlets, only three Trichoderma isolates could be tested in planta. They were selected based on the results of the antibiosis assay: two isolates (LA279 and LA278) showing the highest antagonistic potential against $C$. cassiicola, and a third one 
(T2) with no significant antibiosis effect. LA278 and LA279 were obtained from wild $H$. guianensis trees; we verified for one of them (LA279) whether or not endophytism in $H$. brasiliensis was possible.

Biocontrol tests using in vitro plantlets obtained by somatic embryogenesis. Twelve plantlets directly obtained from somatic embryogenesis, homogeneous in size and presenting three to six leaflets, were used in this experiment. CCP and Trichoderma inoculations were performed in glass tubes, under axenic conditions: $500 \mu \mathrm{l}$ of a spore suspension $\left(5,000\right.$ conidia $\mathrm{ml}^{-1}$ in $0.25 \%$ gelatin) was applied with a sterile (autoclaved) pencil to the upper and lower face of the leaves, and on the stem. Three groups of three plantlets were inoculated with spores from Trichoderma isolates LA278, LA279, and T2 respectively. Three plantlets were mock inoculated with $0.25 \%$ gelatin (control group). After 1 week, one leaflet per plantlet was collected and deep frozen in liquid nitrogen for molecular analysis (RNA extraction). Then, both control and Trichoderma-inoculated plantlets were inoculated with C. cassiicola isolate CCP $\left(5,000\right.$ conidia $\mathrm{ml}^{-1}$ in $0.25 \%$ gelatin), applied with a sterile pencil, as described above. New leaflets were then collected 2 and 5 days after CCP inoculation and immediately deep frozen.

Evaluation of the endophytism by Trichoderma isolate LA279 in rubber plantlets. To verify whether Trichoderma isolate LA279 was able to colonize $H$. brasiliensis as a systemic (or at least widespread) endophyte, we used plantlets micropropagated by in vitro cutting. We selected 18 plantlets that had developed both shoots and roots, approximately 1 month after the last microcutting. Plantlets were inoculated by placing a freshly grown LA279 mycelium plug (6 $\mathrm{mm}$ in diameter) on the culture medium, in contact with the plant stem. Although it may favor slight variations in the amount of inoculum applied, this technique (versus the inoculation technique described above) reduces the risk of damaging the leaves. Nine plantlets were inoculated with Trichoderma isolate LA279 and nine others (control plantlets) with a mycelium-free PDA plug. New subculturing (microcutting) was performed at various time points $(14,21$, and 28 days) after inoculation in groups of six plantlets (three inoculated and three controls at each time point). Leaf, stem, and root pieces were sampled during subculturing, when available, to verify the endophytic colonization of the plantlets by Trichoderma isolate LA279. To do so, the samples were surface sterilized through sequential immersion in $70 \%$ ( $\mathrm{vol} / \mathrm{vol}$ ) ethanol for 2 to $3 \mathrm{~s}, 3 \%$ (degree of chlorine) sodium hypochlorite solution for $1 \mathrm{~min}, 70 \%$ ( $\mathrm{vol} / \mathrm{vol}$ ) ethanol for $30 \mathrm{~s}$, and sterilized water for $1 \mathrm{~min}$. The surface-sterilized explants were then cut into smaller pieces, placed on malt-extract-agar culture medium (Fluka; Sigma-Aldrich), and incubated at 25 to $26^{\circ} \mathrm{C}$ in the dark for up to 1 week. The emerging mycelium was subcultured on PDA. DNA was extracted and two amplicons were sequenced for molecular identification. The first amplicon was amplified from the ITS of the nuclear ribosomal DNA region, using primers ITS1 and ITS4 (White et al. 1990). The second amplicon was amplified from the tefl gene using primers LA-EF1 $\alpha$-I-F1 (5'-cgaaatcatcattctaacgtg- $\left.3^{\prime}\right)$ and qEF1 $\alpha$-R1 (5'gcctcgaactcaccagtacc $\left.-3^{\prime}\right)$. These two primers specifically amplify $123 \mathrm{bp}$ of the tef1 gene from T. koningiopsis isolates LA278 and LA279 but not from $T$. harzianum isolate $\mathrm{T} 2$ or $C$. cassiicola isolate CCP. This specificity is conferred by the sense primer (LA-EF1 $\alpha$-IF1), which was designed from a variable intronic region of the LA279 tefl gene. PCR amplifications (for both ITS and tef1) were performed for 30 cycles $\left(45 \mathrm{~s}\right.$ at $94^{\circ} \mathrm{C}, 45 \mathrm{~s}$ at $55^{\circ} \mathrm{C}$, and $45 \mathrm{~s}$ at $72^{\circ} \mathrm{C}$ ).

To further validate the endophytism of LA279 in H. brasiliensis, we inoculated a potted plant initially obtained by somatic embryogenesis and acclimated in a greenhouse for approximately 1 month. Leaves were sprayed with a spore suspension from isolate LA279 (5,000 conidia ml-1 in $0.25 \%$ gelatin); then, the whole plant was covered with a plastic bag to maintain maximum humidity.
Leaves were collected 14 days postinoculation (dpi) and processed for endophyte isolation and molecular analysis, as described above.

Analysis of the mycelial activity by reverse-transcription quantitative PCR. Colonization of $H$. brasiliensis by the pathogenic $C$. cassiicola isolate CCP was monitored through the expression analysis of a $C$. cassiicola-specific housekeeping gene (tefl) normalized with a reference housekeeping gene from rubber trees (polyubiquitine), as described previously (Déon et al. 2012b). In this experiment, we assumed that mycelial activity reflects mycelial development because it is based on a fungal housekeeping gene.

Total RNA was extracted from leaves using cetyltrimethylammonium bromide extraction buffer, as described previously (Chang et al. 1993). First-strand cDNA was synthesized from $1 \mu \mathrm{g}$ of total RNA using SuperScript III (Invitrogen), following the manufacturer's instructions. Real-time PCR amplification was performed using a MyiQ thermocycler (Bio-Rad) and the Mesa Green qPCR MasterMix Plus (Eurogentec) mixed with $2 \mu \mathrm{l}$ of 40 -fold diluted cDNA and $200 \mathrm{nM}$ each primer (15- $\mu 1$ final volume) according to the manufacturer's recommendations. Primers used to monitor CCP mycelial activity were Cc-qEF1 $\alpha-F 1\left(5^{\prime}\right.$-caccgtcattgacgcccc- $\left.3^{\prime}\right)$ and Cc-qEF1 $\alpha-\mathrm{R} 11$ (5'-gccaatacctccaatcttgtac- $\left.3^{\prime}\right)$, specifically targeting the tefl gene from $C$. cassiicola. The sense primer CcqEF1 $\alpha-F 1$ overlaps an intron and the reverse primer Cc-qEF1 $\alpha-$ R11 targets a polymorphic region. These two primers amplify a 526-bp cDNA fragment from $C$. cassiicola (isolate CCP) but no cDNA product from $H$. brasiliensis leaves or Trichoderma mycelium (isolates T2, LA278, and LA279). PCR were run in triplicate for 40 cycles $\left(15 \mathrm{~s}\right.$ at $95^{\circ} \mathrm{C}, 20 \mathrm{~s}$ at $62^{\circ} \mathrm{C}$, and $20 \mathrm{~s}$ at $72^{\circ} \mathrm{C}$ ).

The reference used in the reverse-transcription quantitative (RT-q)PCR experiment was a $H$. brasiliensis polyubiquitine gene, targeted by the primers Hb-Ubi-F (5'-ttttcgtgaaaaccctcacc- $\left.3^{\prime}\right)$ and $\mathrm{Hb}$-Ubi-R ( $5^{\prime}$-ccgtcttcaagctgtttcc- $\left.3^{\prime}\right)$. PCR were run in triplicate for 40 cycles $\left(15 \mathrm{~s}\right.$ at $95^{\circ} \mathrm{C}, 20 \mathrm{~s}$ at $57^{\circ} \mathrm{C}$, and $20 \mathrm{~s}$ at $\left.72^{\circ} \mathrm{C}\right)$.

The tefl relative gene expression (RE) was calculated at each time point using the following formula: $\mathrm{RE}=\left[\left(\mathrm{E}_{\text {target }}+1\right)\left(-\mathrm{Ct}_{\text {target }}\right)\right] /$ $\left.\left(\mathrm{E}_{\mathrm{ref}}+1\right)\left(-\mathrm{Ct}_{\mathrm{ref}}\right)\right]$, where E represents the primer efficiency, "target" refers to the Cc-EF1 $\alpha$ gene, and "ref" refers to the polyubiquitin reference gene.

CCP and LA279 in vitro growth profiles. Biocontrol experiments in planta require that both the antagonist and pathogen are adapted to the same environment. To determine the optimum temperatures of C. cassiicola isolate CCP and Trichoderma isolate LA279, growth profiles were compared on three culture media, under five temperatures $\left(15,20,25,30\right.$, and $\left.35^{\circ} \mathrm{C}\right)$. Culture media were PDA (Difco), CMD (Difco corn meal extract at $2 \mathrm{~g} / \mathrm{liter}$, dextrose at $10 \mathrm{~g} / \mathrm{liter}$, and agar at $15 \mathrm{~g} /$ liter) and synthetic nutrientpoor agar (SNA; $\mathrm{KH}_{2} \mathrm{PO}_{4}$ at $1 \mathrm{~g} / \mathrm{liter}, \mathrm{KNO}_{3}$ at $1 \mathrm{~g} / \mathrm{liter}$, $\mathrm{MgSO}_{4} \cdot 7 \mathrm{H}_{2} \mathrm{O}$ at $0.5 \mathrm{~g} /$ liter, $\mathrm{KCl}$ at $0.5 \mathrm{~g} /$ liter, glucose at $0.2 \mathrm{~g}$ / liter, saccharose at $0.2 \mathrm{~g} / \mathrm{liter}$, and agar at $20 \mathrm{~g} / \mathrm{liter}$ ). Each condition was analyzed in triplicate. Each mycelial plug was placed $2 \mathrm{~cm}$ from the plate border. Plates were incubated in the dark for up to 4 days. The colony radius was recorded at 24,48 , and $72 \mathrm{~h}$ (before the Trichoderma colonies had fully covered the medium).

\section{RESULTS}

GI in dual-culture assays and mycoparasitism. Fungal endophytes previously isolated from rubber trees in Peru (Gazis and Chaverri 2010, 2015) (Table 1) were tested against a virulent C. cassiicola isolate (CCP) in a dual-culture assay (Fig. 1). These endophytes belonged to various species from three genera: Colletotrichum, Pestalotiopsis, and Trichoderma. Inhibitory effect toward CCP was observed by all the isolates, with GI\% ranging from 22 to $33 \%$ for Pestalotiopsis isolates, 17 to $30 \%$ for Colletotrichum isolates, and 13 to $38 \%$ for Trichoderma isolates. In this data set, Pestalotiopsis isolates were, on average, more inhibitory than isolates from the other two genera, although the 
difference was not significant $(P=0.09)$. GI was not related to the endophyte species. Indeed, isolates of the same species such as $\mathrm{H} 10$ and T2 (T. lentiforme) showed contrasted GI\%. The seven T. endophyticum isolates tested displayed a broad range of GI\%, from the lowest $(\mathrm{T} 7=12.9 \%)$ to the second highest $(\mathrm{MS} 437=$ $33.9 \%$ ). GI\% was not significantly influenced by either the host species ( $H$. brasiliensis versus $H$. guianensis), host context (cultivated versus wild), or host tissue (leaf versus sapwood) in this data set.

In the case of Pestalotiopsis and Colletotrichum isolates, the antagonism was reciprocal: both colonies stopped growing when in contact with or in close proximity to each other (Fig. 2). In contrast, Trichoderma isolates continued to grow after contact with CCP, rapidly covering the entire colony and finally sporulating on the pathogen's colony surface. To further confirm antagonism of Trichoderma toward CCP, a small piece of paper covered with freshly grown Trichoderma mycelium was placed on top of a CCP mycelial colony, without direct contact with the culture medium. All Trichoderma isolates tested were able to grow and colonize the entire CCP colony. Conversely, no CCP growth was observed when a piece of paper covered with CCP mycelium was placed on top of a Trichoderma colony, regardless of the isolate. Microscopy observations of dual cultures, in the confrontation zone between CCP and Trichoderma isolate LA279, revealed tight associations between the two mycelia, with putative coiling of LA279 around CCP, as well as LA279 hyphae growing apparently inside of (or along) CCP hyphae (Supplementary Fig. S1). This strongly supports the hypothesis that LA279 might be able to parasitize
CCP. However, further investigation would be necessary to demonstrate this with certainty.

Antibiosis assays. Twenty-one Trichoderma isolates were tested for their capacity to antagonize $C$. cassiicola isolate $\mathrm{CCP}$ through the secretion of growth-inhibiting molecules (antibiosis). The antibiosis test consisted of measuring CCP growth on PDA medium supplemented with various Trichoderma filtrates compared with control plates (i.e., PDA medium supplemented with CCP filtrate or CZ only) (Figs. 3 and 4). Filtrates from LA279 and LA278 had a clear inhibitory effect on CCP growth 2 and 5 dpi (Fig. 3 ), although only the LA279 effect was found to be statistically significant (Student-Newman-Keul test, $P<0.05$ ). After 9 days (Fig. 4), CPP colony diameter in the presence of LA279 filtrate was only $37 \mathrm{~mm}$ on average whereas it had fully covered the medium in control plates or in plates containing other filtrates. After 12 days, plates containing LA279 filtrate were finally fully covered, indicating that $\mathrm{CCP}$ growth was reduced but not completely inhibited by this filtrate.

In planta antagonism. The Trichoderma isolates LA279 and LA278, which had shown the highest inhibitory potential against C. cassiicola in the antibiosis assay (Figs. 3 and 4), were further analyzed in planta. Both isolates were identified as T. koningiopsis and were isolated from sapwood of $H$. guianensis. A third isolate (T2) that showed no significant antibiosis effect was included as a comparison. T2 was identified as T. lentiforme and was isolated from sapwood of $H$. brasiliensis. For the in planta assays, we used sterile in vitro plantlets directly obtained by somatic embryogenesis or propagated by microcutting.

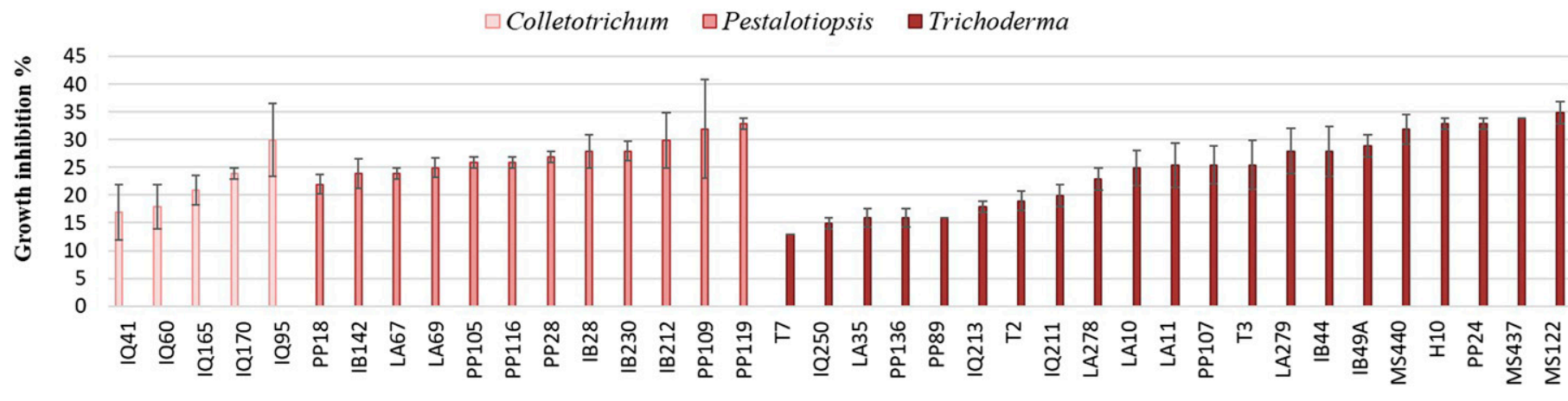

Fig. 1. Results from the dual-culture antagonistic assay. Growth inhibition percentage (GI\%) of Corynespora cassiicola (CCP isolate) after confrontation with rubber tree endophytes belonging to three genera (Colletotrichum, Pestalotiopsis, and Trichoderma). GI\% was calculated from the mean radial growth of three replicates in comparison with the controls (CCP alone).
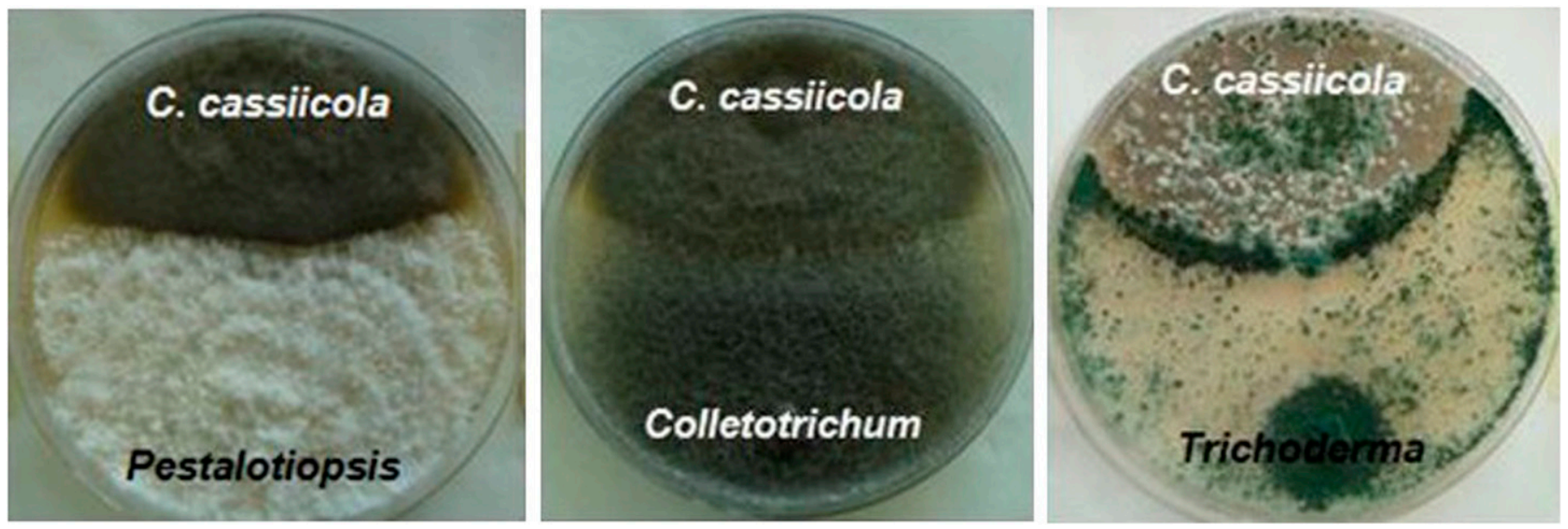

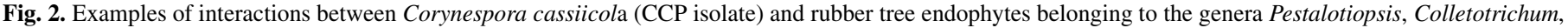
and Trichoderma in dual cultures. 
In vitro plantlets directly obtained from somatic embryogenesis were used to conduct the biocontrol experiment under axenic conditions. The plantlets were preinoculated in vitro with spores of selected Trichoderma isolates (LA278, LA279, or T2) or mock inoculated with sterile water. After 1 week, one leaflet from each plantlet was collected for analysis (time point 0 ); then, the plantlets were inoculated with spores of the pathogen $\mathrm{CCP}$, and leaflets were collected again at 2 and $5 \mathrm{dpi}$. CCP mycelial activity was estimated from the relative expression of a housekeeping gene, tefl, measured by RT-qPCR using $C$. cassiicola-specific primers, relative to a H. brasiliensis polyubiquitine gene (Fig. 5). CCP mycelial activity was measured at all time points $(0,2$, and $5 \mathrm{dpi})$ but only detected at 2 and $5 \mathrm{dpi}$. The absence of detection at time 0 , regardless of the pretreatment, confirms that the primers are specific to the pathogen (unable to amplify tefl cDNA from either Trichoderma or the rubber tree). The highest mycelial activity was detected on the pathogen control plantlets pretreated with water only, suggesting an active development of the pathogen CCP. This activity was significantly lower in plantlets preinoculated with the Trichoderma isolates LA278 and LA279. Pretreatment with T2 reduced CCP mycelial activity, although not significantly according to Tukey's HSD test. These results were validated by the visual symptoms (Fig. 6 ), in which a high density of necrotic leaf spots was observed on the control plants, only a few visible leaf spots on the plantlets preinoculated with isolate $\mathrm{T} 2$, and no visible symptoms on the plantlets preinoculated with LA278 and LA279. These results suggest that preinoculation with these two Trichoderma isolates can protect the rubber plantlets against the pathogen $C$. cassiicola by reducing its development.

To verify that Trichoderma can systemically and endophytically colonize rubber tree plantlets, we inoculated plantlets propagated by microcutting with a mycelial plug from the antagonist T. koningiopsis isolate LA279, under laboratory conditions. Tissue samples (leaf, root, and stems) were collected 2, 3, or 4 weeks after inoculation. Pieces were surface sterilized, plated on culture medium, and incubated. All control (noninoculated) plantlets were confirmed free of endophytic fungi, whereas a single fungal isolate was obtained for all of the inoculated plantlets, regardless of the time point or the tissue tested. This isolate was confirmed to be Trichoderma sp. according to ITS sequencing, and most certainly LA279, because the tef1 amplicons obtained from both the reisolated fungus and LA279 mycelium were found to be identical. Thus, this experiment demonstrated the ability of LA279 to colonize rubber plantlets endophytically and systemically, from roots to leaves, as soon as 2 weeks after inoculation. To further validate the ability of LA279 to become a systemic endophyte of rubber trees, we spray inoculated the leaves of a potted plant with a spore suspension. All leaves remained healthy for up to 1 month. Leaves were collected 14 days after inoculation and processed for endophyte isolation. The only fungal isolate obtained was identified as LA279 based on ITS and tef1 sequences.

Comparison of CCP and LA279 growth profiles. To test whether the optimum temperatures of $C$. cassiicola isolate CCP and Trichoderma isolate LA279 were compatible for biocontrol applications, we compared their total colony growth in vitro over a 72-h period on different culture media and at different temperatures (Fig. 7), in a range compatible with the average climatic environment of rubber plantations. LA279 grew faster than $\mathrm{CCP}$, regardless of temperature or culture medium. For both isolates, the optimal temperature was between 25 and $30^{\circ} \mathrm{C}$. CCP was able to grow at $35^{\circ} \mathrm{C}$ but at a reduced pace. LA279 failed to grow at $35^{\circ} \mathrm{C}$ on any culture medium. Growth was significantly influenced by the culture medium. PDA medium was clearly the most efficient and SNA the least efficient in promoting LA279 growth. For CCP, the PDA and CMD media gave similar growth profiles while SNA was less efficient at all temperatures except $35^{\circ} \mathrm{C}$.

\section{DISCUSSION}

In this study, we explored in vitro and in planta (under laboratory conditions) the potential of a selected set of fungal endophytes, isolated from rubber trees distributed in their native range, as biocontrol agents against the causal agent of the economically important CLF disease of rubber tree. The tested endophytes belong to three genera: Pestalotiopsis and Trichoderma, frequently isolated mostly from leaves and sapwood of wild rubber trees (Gazis and Chaverri 2010), and Colletotrichum, frequently isolated from the leaves of both wild (Araújo et al. 2018) and cultivated (Déon et al. $2012 b$ ) rubber trees. Depending on the host plant species, health state, and cultural conditions, Colletotrichum and Pestalotiopsis can be either avirulent or pathogenic, inducing localized lesions with negligible economic importance or severe disease symptoms (Cannon et al. 2012; Maharachchikumbura et al. 2014). In contrast, Trichoderma spp. are not considered to be plant pathogens, except in rare cases of pathogenic isolates causing disease in apple, maize, or alfalfa (Harman et al. 2004). Trichoderma spp. have been extensively described as soil inhabitants colonizing the rhizosphere,

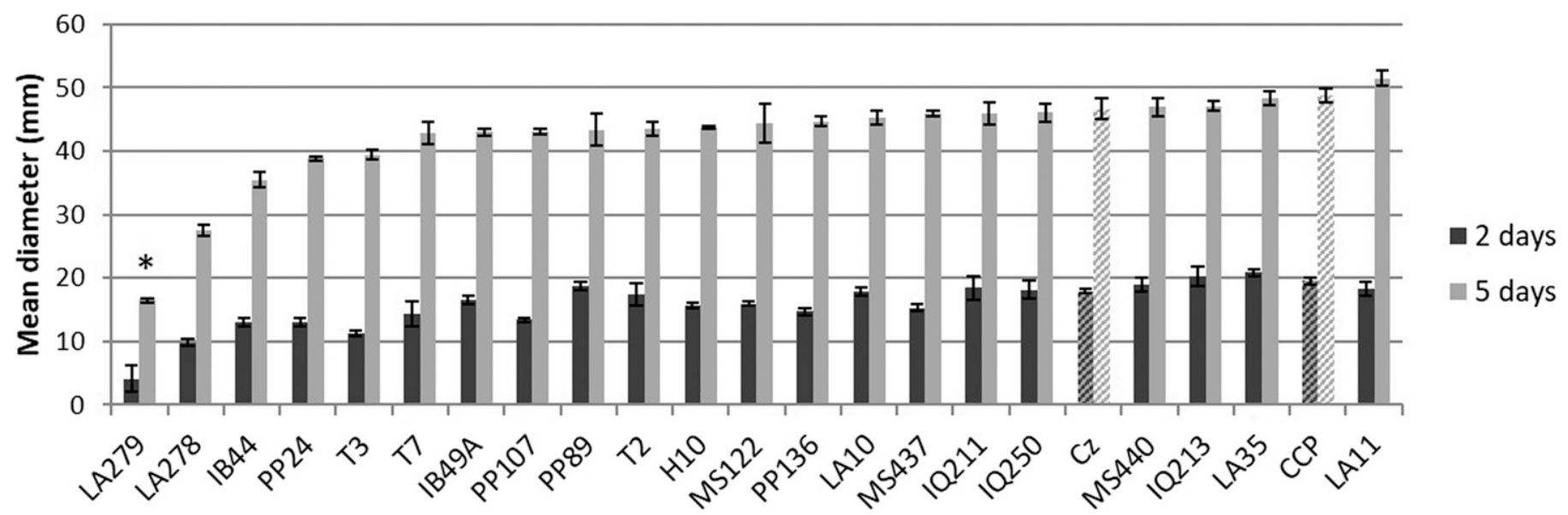

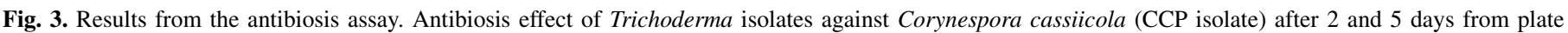

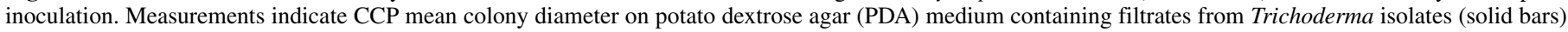

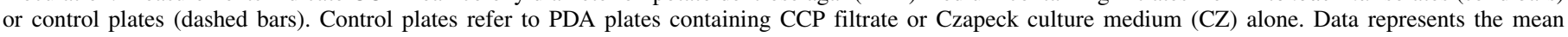

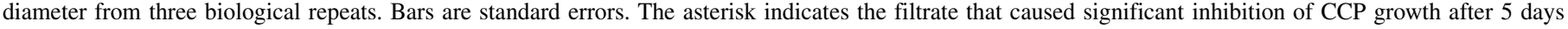
compared with the controls $(\mathrm{CZ}$ and $\mathrm{CCP})$, according to the Student-Newman-Keul test $(P<0.05)$. 
or as endophytes (Bailey et al. 2008; Harman et al. 2004). They develop beneficial interactions with the plants, either directly by promoting growth and stimulating the plant defenses against biotic and abiotic stresses, or indirectly by antagonizing the fungal phytopathogens (Contreras-Cornejo et al. 2016). The mechanisms leading to this antagonism may involve competition for nutrients, secretion of soluble or volatile substances with antibiotic effect, or mycoparasitism (Inácio et al. 2006; Li et al. 2008; Tejesvi et al. 2007; Vos et al. 2015). For all of these properties, Trichoderma spp. have attracted much interest as biocontrol agents (Harman et al. 2004, 2010).

Most of the endophytes tested in dual culture in this study had an antagonist effect toward C. cassiicola isolate CCP. The differences

\section{Antibiosis}

60

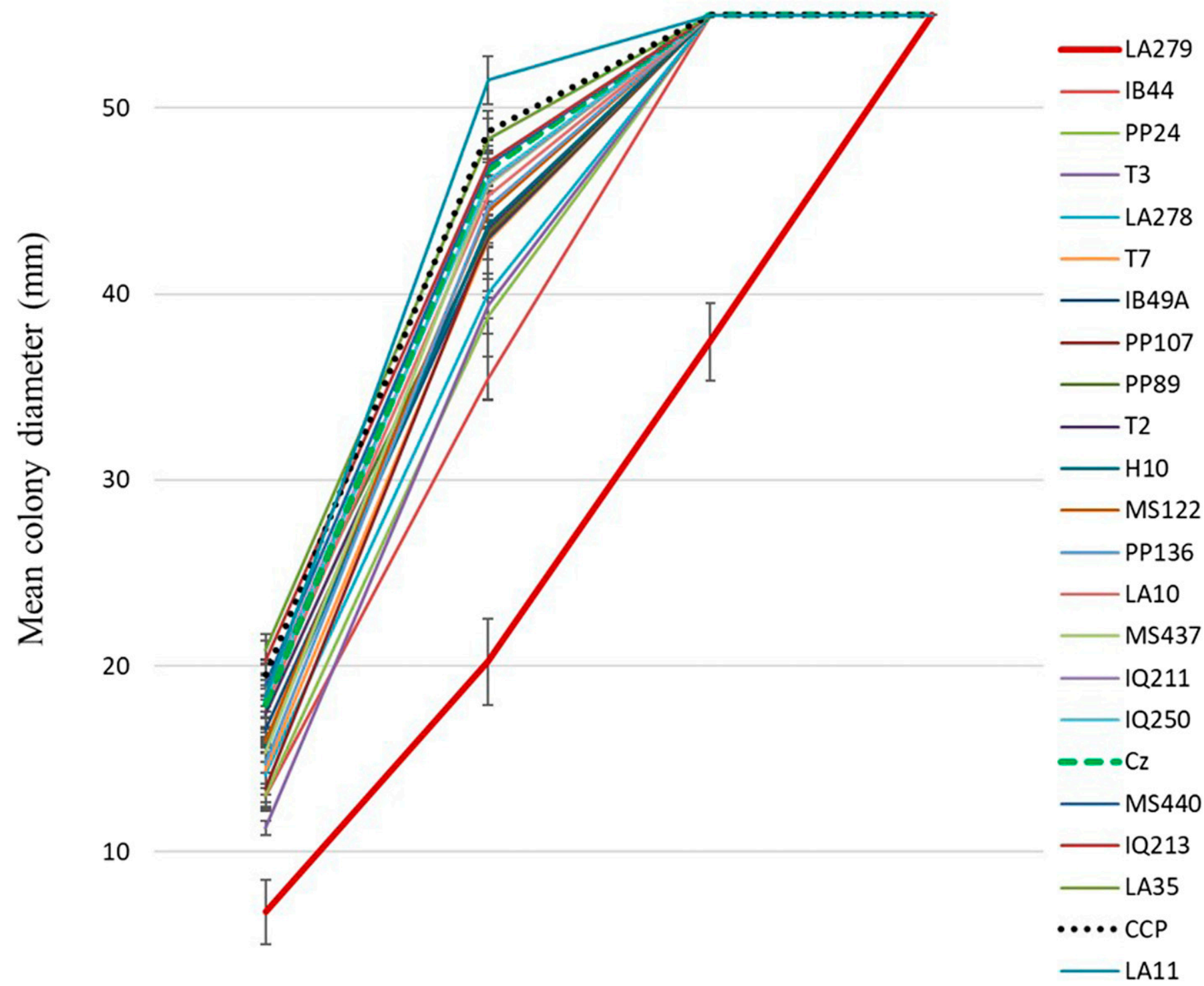

0

2 days $\quad 5$ days $\quad 9$ days $\quad 12$ days

Days of culture

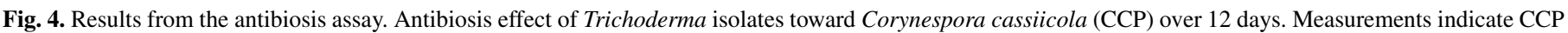

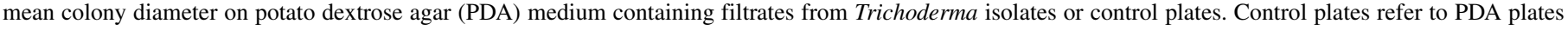

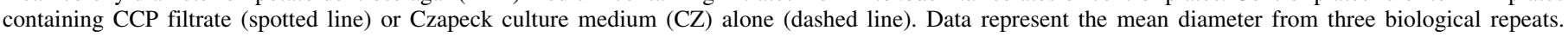

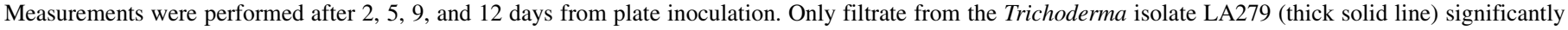
inhibited the growth of CCP in comparison with other Trichoderma filtrates or controls (CCP filtrate and CZ). 
in GI\% could not be related to the endophyte genus or species, or to their provenance (host species, location, or tissue). However, differences in growth rate among the various isolates may have influenced their ranking in this assay: fast-growing endophytes may be more competitive for nutrients than slower-growing endophytes and initiate antagonism earlier, as soon as they (or their metabolites) get close enough to affect the CCP colony. Nevertheless, this experiment showed that the antagonistic effect of the Trichoderma isolates toward CCP differed consistently from that of the Colletotrichum and Pestalotiopsis isolates. Indeed, only Trichoderma could grow and sporulate over a CCP colony, while the others rather behaved as mutual antagonists. Our microscopic observations showed the probable penetration of Trichoderma isolate LA279 inside CCP hyphae, suggesting that mycoparasitism may be part of the mechanisms involved in CCP GI by LA279. This was not tested for the other isolates. Mycoparasitism is not an obligate trait of all Trichoderma spp., although it often occurs (Druzhinina et al. 2011; Harman et al. 2004). As an example, Bae et al. (2011) analyzed six Trichoderma isolates of various species for their capacity to parasitize Phytophthora capsici and found diverse situations, including penetration without significant coiling (two isolates), intense coiling without penetration (one isolate), parallel associations without penetration (two isolates), or no sign of physical association (one isolate). Phylogenetic and genomic approaches have suggested that the ancestor of Trichoderma was a mycoparasite, and have shown that many lineages rapidly evolved to become saprotrophs or endophytes, thus gaining new ecological niches (Chaverri and Samuels 2013; Kubicek et al. 2011).

Antibiosis is another frequent mechanism used by Trichoderma to antagonize other microorganisms such as fungal phytopathogens (Contreras-Cornejo et al. 2016). Trichoderma spp. produce a wide array of secondary metabolites with antibiotic properties (peptaibols, nonribosomal peptide synthetases, terpenes, pyrones, and siderophores, among others), as well as fungal cell-wall-degrading enzymes (e.g., chitinases and $\beta$-1,3-glucanases), potentially required for mycoparasitism but also directly affecting the growth of the fungal pathogen in antibiosis assays. In this study, of the 21 Trichoderma filtrates tested in the antibiosis assay, only LA279 filtrate significantly delayed CCP growth (57\% inhibition after 5 days of culture), although it did not completely stop it. Ranking of the isolates based on culture filtrate activity was not concordant to the ranking obtained from the dual-culture experiments $\left(R^{2}=\right.$ $0.0455)$. As an example, isolate MS122 was very efficient in the dual-culture assay ( $>35 \%$ GI) but had no significant antibiosis effect. Isolates LA279 and LA278, ranking 1st and 2nd, respectively, for antibiosis, only ranked 9th and 15th in the dualculture assay. In the dual cultures, several mechanisms may jointly contribute to the antagonistic effect, including antibiosis caused by soluble or volatile compounds, competition for nutrients, and mycoparasitism. This may explain ranking discrepancies between the two experiments. In addition, differences in culture conditions between both experiments (PDA plates in the dual-culture assay versus liquid $\mathrm{CZ}$ in the antibiosis assay) may also have induced differences in the production of antibiotic molecules by the Trichoderma isolates.

The use of multiple mechanisms to restrain pathogens development, both in vitro and in planta, has been well documented. In the interaction between Trichoderma isolates and P. capsici (Bae et al. 2011), one Trichoderma isolate was clearly both parasitic and able to inhibit the growth of the pathogen through antibiosis. Conversely, another isolate completely prevented growth of $P$. capsici through antibiosis but could apparently not parasitize it. In addition to these antagonistic mechanisms, the same study also demonstrated the induction of plant defense genes in response to Trichoderma isolates, with various expression patterns depending on the isolates. Trichoderma spp. are known to induce systemic resistance in plants which can contribute to suppress plant disease (Bailey et al. 2008; Harman et al. 2004; Vos et al. 2015).
To verify in our pathosystem whether the fungus-fungus antagonism also operates in planta, and whether it may be used to protect the rubber tree against $C$. cassiicola, we set up experiments on sterile $H$. brasiliensis plantlets of the susceptible clone PB260. This in vitro material offered the possibility to analyze specific axenic fungal strains, without possible interference from other endogenous endophytes. We selected three Trichoderma isolates for this analysis: LA279 and LA278, for their high and medium antibiosis effect (respectively), and one isolate (T2) with lower effect, ranking 10th in antibiosis assay and 7th in the dual-culture assay, for comparison. One-week preinoculation with LA279 and LA278 significantly reduced CCP mycelial activity (reflecting mycelial development) and symptoms. Preinoculation with T2 also had a small antagonistic effect, although not significant. These results are concordant with those obtained in the direct fungal confrontation tests (dual culture and antibiosis), suggesting that mycoparasitism or antibiosis may jointly contribute to the inhibition of CCP development in planta, under our laboratory conditions. Additionally, all three Trichoderma isolates may potentially have induced plant defenses (which may explain the small effect of the preinoculation with $\mathrm{T} 2$, although this isolate showed no significant antibiosis capacity) but we did not test this hypothesis.

In our study, all Trichoderma isolates were endophytes collected from Hevea spp. The two candidates with best antibiosis potential against $C$. cassiicola isolate CCP (LA279 and LA278) were isolated from $H$. guianensis trees in Peru. $H$. guianensis is a noncultivated sister species of the commercial rubber tree $H$. brasiliensis. Thus, it was important to verify whether these two isolates could colonize $H$. brasiliensis. We demonstrated that isolate LA279, inoculated on $H$. brasiliensis as a mycelium plug at the collar of plantlets (under laboratory conditions) or as spore suspension on an acclimated plant, was able to endophytically and systemically infect and colonize the host. One may wonder whether endophytic Trichoderma isolates with mycoparasitic capacity derive their nutrients from the host plant or by parasitizing other fungal endophytes. Because the in vitro plantlets used in our experiment were free of

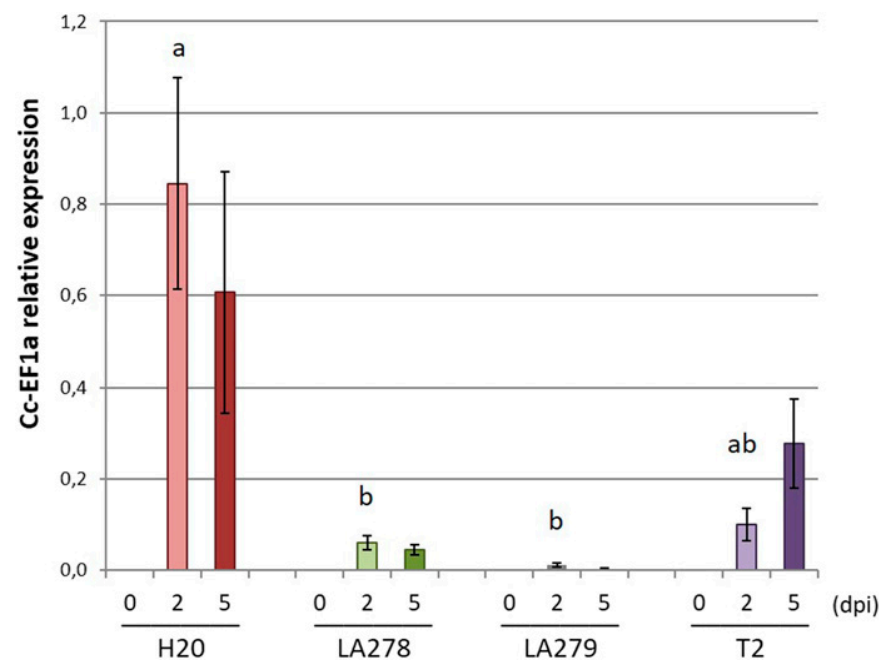

Fig. 5. Results from in planta assays: Corynespora cassiicola mycelial activity in rubber plantlets preinoculated with Trichoderma isolates. In vitro soma plantlets were preinoculated with water $\left(\mathrm{H}_{2} \mathrm{O}\right)$ or with Trichoderma isolates LA278, LA279, and T2 1 week before inoculation with the C. cassiicola virulent isolate CCP. Leaves were collected just before inoculation with CCP ( 0 days postinoculation [dpi]) and then 2 and 5 dpi. Relative expression of the C. cassiicola-specific translation elongation factor $1 \alpha(t e f 1)$ gene was analyzed using a Hevea brasiliensis-specific ubiquitin gene as reference. Control plantlets were inoculated with water. Three biological repeats were analyzed. Bars represent standard error. Data were analyzed using analysis of variance. Letters indicate the significance of between-group differences (Tukey's honestly significant difference HSD test, $\alpha=0.05$ ). 
endophytes (confirmed by the fact that no fungal species could be isolated from control plantlets), we assume that LA279 is able to survive in the plant independently of mycoparasitism. This endophytic ability offers interesting perspectives for preventive protection of the cultivated rubber tree against $C$. cassiicola. Previous studies showed that wild rubber trees host a wider diversity of fungal species, including Trichoderma spp., compared with cultivated rubber trees (Gazis and Chaverri 2015). A recent article also mentioned the presence of Trichoderma spp. in stems and roots of $H$. guianensis from the Brazilian Amazon but the isolates (not characterized at species level) were not evaluated as potential biocontrol agents (Araújo et al. 2018). Our results confirm the idea that wild rubber trees may be reservoirs of endophytes with antagonizing potential toward pathogens.
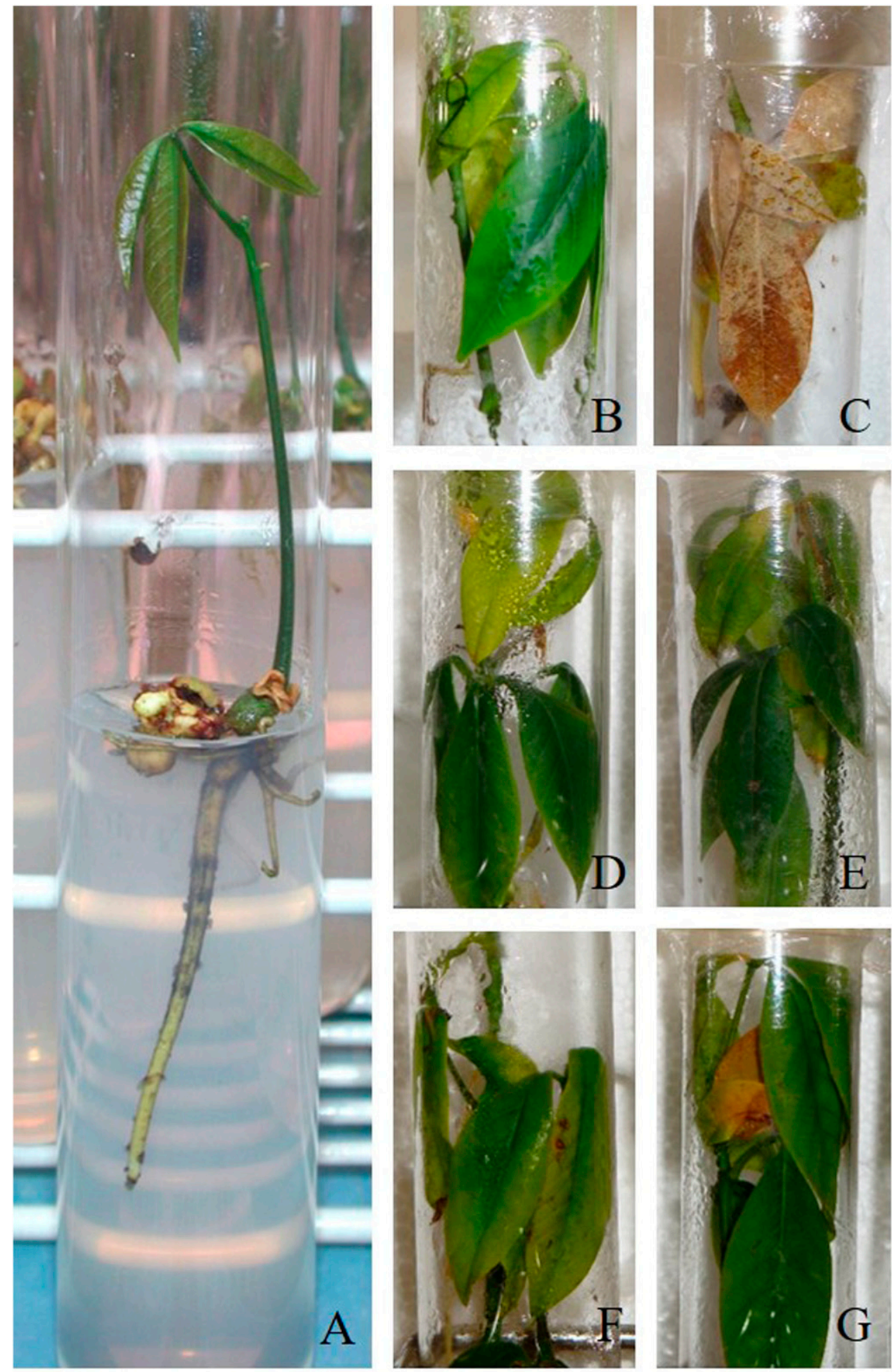

Fig. 6. Results from the in planta assay. Symptoms induced by Corynespora cassiicola in rubber plantlets preinoculated or not with Trichoderma isolates. A, In vitro soma plantlet; $\mathbf{B}$ and $\mathbf{C}$, control plants preinoculated with water; D and E, plants preinoculated with spores from Trichoderma isolate LA279; and $\mathbf{F}$ and $\mathbf{G}$, plants preinoculated with spores from Trichoderma isolates T2. One week after preinoculation, plants were inoculated with spores from the pathogenic isolate CCP (C, E, and G) or mock inoculated again with water (B, D, and F). Photos were taken 21 days after pathogen inoculation. 
Interestingly, both antagonist candidates (LA278 and LA279) belong to the T. koningiopsis species complex. They were isolated from sapwood, together with other Trichoderma spp. (T. endophyticum, $T$. amazonicum, and T. harzianum). T. koningiopsis is a cosmopolitan species complex with a pan-global distribution (Atanasova et al. 2013; Samuels et al. 2006; Zachow et al. 2016). It is the most frequent Trichoderma species complex found as an endophyte in the phloem tissues of woody plants, together with several species in the T. harzianum species complex (Chaverri et al. 2015; Gazis and Chaverri 2010; Rocha et al. 2017). It was previously described as a potential biocontrol agent against Sclerotium rolfsii in chickpea (Saxena et al. 2015). T. koningiopsis isolates produce secondary metabolites known as koningiopisins, which display antifungal activities in vitro (Hu et al. 2017; Liu et al. 2016a,b) that could lead to promising medical or agricultural applications. The molecules secreted by LA279 behind the antibiosis effect toward C. cassiicola are so far unknown but grant characterization.

As an endophyte of Hevea spp. isolated in the center of origin of the rubber tree, LA279 is most likely adapted to the rubber tree habitat and could possibly be used as a biocontrol agent against C. cassiicola, although rubber plantations and undisturbed Amazonian forests are very different biotopes. We verified through growth tests that both fungi had similar optimum temperatures in vitro. However, T. konigiopsis LA279 was more sensitive to high temperatures than $C$. cassiicola isolate $\mathrm{CCP}$, which may compromise an in situ biocontrol strategy. This would have to be further tested in planta, under field conditions characteristic of rubber plantations.
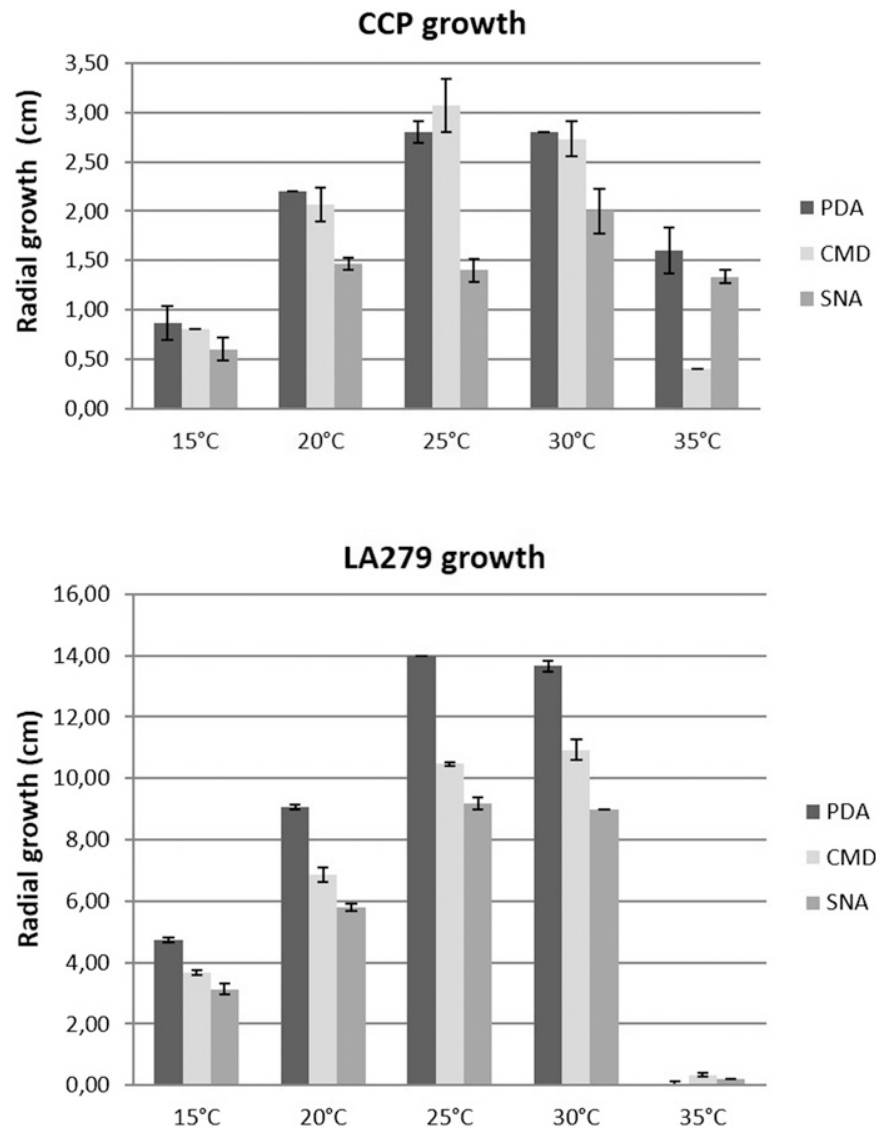

Fig. 7. Comparison of the growth profiles of $\mathbf{A}$, Corynespora cassiicola isolate CCP and B, Trichoderma koningiopsis isolate LA279 on three media (potato dextrose agar [PDA], corn meal dextrose agar [CMD], and synthetic nutrientpoor agar [SNA]) and at five temperatures $\left(15,20,25,30\right.$, and $\left.35^{\circ} \mathrm{C}\right)$. Colony radial growth (in centimeters) was measured after $72 \mathrm{~h}$ from plate inoculation and incubation under dark. Data represent the mean of three replicates. Bars represent standard error.
Conclusion. We identified T. koningiopsis isolate LA279, endophyte of the wild rubber tree species $H$. guianensis, as a promising biocontrol agent for the protection of commercial rubber trees ( $H$. brasiliensis) against the leaf pathogen $C$. cassiicola. The protective action of isolate LA279 may involve mycoparasitism, together with (or mediated by) the secretion of antifungal molecules. The antibiosis capacity is of particular interest for the development of a biofungicide specifically targeting $C$. cassiicola. In addition, the capacity of LA279 to colonize rubber trees systemically, as an endophyte, offers the possibility to use it as a microbial-based biocontrol agent to limit the damages associated with $C$. cassiicola infection, as demonstrated in this study on sterile in vitro plantlets. Further analysis will be necessary to verify the efficiency of LA279 in both preventive and curative applications on acclimated whole plants.

\section{ACKNOWLEDGMENTS}

We thank F. Giraud, M.-A. Mathat, K. Haro, S. Labernia, and S. Gaurel for technical assistance in this study.

\section{LITERATURE CITED}

Araújo, K. S., Brito, V. N., Veloso, T. R., Leite, T. D. S., Pareira, O. L., Mizubuti, E. S. G., and de Queiroz, M. V. 2018. Diversity of culturable endophytic fungi of Hevea guianensis: A latex producer native tree from the Brazilian Amazon. Afr. J. Microbiol. Res. 12:953-964.

Atanasova, L., Druzhinina, I. S., and Jaklitsch, W. M. 2013. Two hundred Trichoderma species recognized on the basis of molecular phylogeny. Pages 10-42 in: Trichoderma: Biology and Applications. P. K. Mukherjee, B. A. Horwitz, U. S. Singh, M. Mukherjee, and M. Schmoll, eds. CABI, Wallingford, U.K.

Bae, H., Roberts, D. P., Lim, H. S., Strem, M. D., Park, S. C., Ryu, C. M., Melnick, R. L., and Bailey, B. A. 2011. Endophytic Trichoderma isolates from tropical environments delay disease onset and induce resistance against Phytophthora capsici in hot pepper using multiple mechanisms. Mol. Plant-Microbe Interact. 24:336-351.

Bailey, B. A., Bae, H., Strem, M. D., Crozier, J., Thomas, S. E., Samuels, G. J., Vinyard, B. T., and Holmes, K. A. 2008. Antibiosis, mycoparasitism, and colonization success for endophytic Trichoderma isolates with biological control potential in Theobroma cacao. Biol. Control 46:24-35.

Barreto, E. S., Torres, A. R., Barreto, M. R., Vasconcelos, A. T., Astolfi-Filho, S., and Hungria, M. 2008. Diversity in antifungal activity of strains of Chromobacterium violaceum from the Brazilian Amazon. J. Ind. Microbiol. Biotechnol. 35:783-790.

Berbee, M. L. 2001. The phylogeny of plant and animal pathogens in the Ascomycota. Physiol. Mol. Plant Pathol. 59:165-187.

Breton, F., Sanier, C., and d'Auzac, J. 2000. Role of cassiicolin, a hostselective toxin, in pathogenicity of Corynespora cassiicola, causal agent of a leaf fall disease of Hevea. J. Rubber Res. 3:115-128.

Cannon, P. F., Damm, U., Johnston, P. R., and Weir, B. S. 2012. ColletotrichumCurrent status and future directions. Stud. Mycol. 73:181-213.

Chang, S., Puryear, J., and Cairney, J. 1993. A simple and efficient method for isolating RNA from pine trees. Plant Mol. Biol. Rep. 11:113-116.

Chaverri, P., and Samuels, G. J. 2013. Evolution of habitat preference and nutrition mode in a cosmopolitan fungal genus with evidence of interkingdom host jumps and major shifts in ecology. Evolution 67:2823-2837.

Chaverri, P., Branco-Rocha, F., Jaklitsch, W. M., Gazis, R. O., Degenkolb, T., and Samuels, G. J. 2015. Systematics of the Trichoderma harzianum species complex and the re-identification of commercial biocontrol strains. Mycologia 107:558-590.

Contreras-Cornejo, H. A., Macias-Rodriguez, L., del-Val, E., and Larsen, J. 2016. Ecological functions of Trichoderma spp. and their secondary metabolites in the rhizosphere: Interactions with plants. FEMS Microbiol. Ecol. 92:fiw036.

de Lamotte, F., Duviau, M. P., Sanier, C., Thai, R., Poncet, J., Bieysse, D., Breton, F., and Pujade-Renaud, V. 2007. Purification and characterization of cassiicolin, the toxin produced by Corynespora cassiicola, causal agent of the leaf fall disease of rubber tree. J. Chromatogr. B Analyt. Technol. Biomed. Life Sci. 849:357-362.

Déon, M., Bourré, Y., Gimenez, S., Berger, A., Bieysse, D., de Lamotte, F., Poncet, J., Roussel, V., Bonnot, F., Oliver, G., Franchel, J., Seguin, M., Leroy, T., Roeckel-Drevet, P., and Pujade-Renaud, V. 2012a. Characterization of a cassiicolin-encoding gene from Corynespora cassiicola, pathogen of rubber tree (Hevea brasiliensis). Plant Sci. 185-186:227-237. 
Déon, M., Fumanal, B., Gimenez, S., Bieysse, D., Oliveira, R. R., Shuib, S. S., Breton, F., Elumalai, S., Vida, J. B., Seguin, M., Leroy, T., Roeckel-Drevet, P., and Pujade-Renaud, V. 2014. Diversity of the cassiicolin gene in Corynespora cassiicola and relation with the pathogenicity in Hevea brasiliensis. Fungal Biol. 118:32-47.

Déon, M., Scomparin, A., Tixier, A., Mattos, C., Leroy, T., Seguin, M., Roeckel-Drevet, P., and Pujade-Renaud, V. 2012b. First characterization of endophytic Corynespora cassiicola isolates with variant cassiicolin genes recovered from rubber trees in Brazil. Fungal Divers. 54:87-99.

Dixon, L. J., Schlub, R. L., Pernezny, K., and Datnoff, L. E. 2009. Host specialization and phylogenetic diversity of Corynespora cassiicola. Phytopathology 99:1015-1027.

Druzhinina, I. S., Seidl-Seiboth, V., Herrera-Estrella, A., Horwitz, B. A., Kenerley, C. M., Monte, E., Mukherjee, P. K., Zeilinger, S., Grigoriev, I. V., and Kubicek, C. P. 2011. Trichoderma: The genomics of opportunistic success. Nat. Rev. Microbiol. 9:749-759.

Evans, H. C. 2002. Invasive neotropical pathogens of tree crops. Pages 83-112 in: Tropical Mycology 2: Micromycetes. R. Watling, J. C. Frankland, A. M. Ainsworth, S. Isaac, and C. H. Robinson, eds. CABI Publishing, Wallingford, U.K.

Evans, H. C. 2008. The endophyte-enemy release hypothesis: Implications for classical biological control and plant invasions Pages 20-25 in: Twelfth Int. Symp. Biol. Control Weeds. M. H. Julien, R. Sforza, M. C. Bon, H. C. Evans, P. E. Thatcher, H. L. Hinz and B. G. Rector, eds. CAB International, Wallingford, U.K.

Farr, D. F., and Rossman, A. Y., eds. 2016. Fungal databases. United States Department of Agriculture-Agricultural Research Service. https://nt.arsgrin.gov/fungaldatabases/

Ferreira-Saab, M., Formey, D., Torres, M., Aragon, W., Padilla, E. A., Tromas, A., Sohlenkamp, C., Schwan-Estrada, K. R. F., and Serrano, M. 2018. Compounds released by the biocontrol yeast Hanseniaspora opuntiae protect plants against Corynespora cassiicola and Botrytis cinerea. Front. Microbiol. 9:1596.

Gasparotto, L., Ferreira, F. A., and Junqueira, N. T. V. 1988. Mancha de Corynespora em folhas de seringueira (Hevea brasiliensis) no Brasil [Corynespora leaf spot of rubber (Hevea brasiliensis) in Brazil]. Fitopatol. Bras. 13:278-280.

Gazis, R., and Chaverri, P. 2010. Diversity of fungal endophytes in leaves and stems of wild rubber trees (Hevea brasiliensis) in Peru. Fungal Ecol. 3: 240-254.

Gazis, R., and Chaverri, P. 2015. Wild trees in the Amazon basin harbor a great diversity of beneficial endosymbiotic fungi: Is this evidence of protective mutualism? Fungal Ecol. 17:18-29.

Hanada, R. E., de Jorge Souza, T., Pomella, A. W., Hebbar, K. P., Pereira, J. O., Ismaiel, A., and Samuels, G. J. 2008. Trichoderma martiale sp. nov., a new endophyte from sapwood of Theobroma cacao with a potential for biological control. Mycol. Res. 112:1335-1343.

Harman, G. E., Howell, C. R., Viterbo, A., Chet, I., and Lorito, M. 2004. Trichoderma species-Opportunistic, avirulent plant symbionts. Nat. Rev. Microbiol. 2:43-56.

Harman, G. E., Obregón, M. A., Samuels, G. J., and Lorito, M. 2010. Changing models for commercialization and implementation of biocontrol in the developing and the developed world. Plant Dis. 94:928-939.

Heckman, D. S., Geiser, D. M., Eidell, B. R., Stauffer, R. L., Kardos, N. L., and Hedges, S. B. 2001. Molecular evidence for the early colonization of land by fungi and plants. Science 293:1129-1133.

Heimpel, G. E., Yang, Y., Hill, J. D., and Ragsdale, D. W. 2013. Environmental consequences of invasive species: Greenhouse gas emissions of insecticide use and the role of biological control in reducing emissions. PLoS One 8: e72293.

Hieu, N. D., Nghia, N. A., Chi, V. T. Q., and Dung, P. 2014. Genetic diversity and pathogenicity of Corynespora cassiicola isolates from rubber trees and other hosts in Vietnam. J Rubber Res 17:187-203.

Hu, M., Li, Q. L., Yang, Y. B., Liu, K., Miao, C. P., Zhao, L. X., and Ding, Z. T. 2017. Koninginins R-S from the endophytic fungus Trichoderma koningiopsis. Nat. Prod. Res. 31:835-839.

Inácio, M. L., Silva, G. H., Teles, H. L., Trevisan, H. C., Cavalheiro, A. J., Bolzani, V. S., Young, M. C. M., Pfenning, L. H., and Araújo, Â. R. 2006. Antifungal metabolites from Colletotrichum gloeosporioides, an endophytic fungus in Cryptocarya mandioccana Nees (Lauraceae). Biochem. Syst. Ecol. 34:822-824.

Kadyan, S., Panghal, M., Kumar, S., Singh, K., and Yadav, J. P. 2013. Assessment of functional and genetic diversity of aerobic endospore forming Bacilli from rhizospheric soil of Phyllanthus amarus L. World J. Microbiol. Biotechnol. 29:1597-1610.

Kim, M. S., Kim, Y. C., and Cho, B. H. 2004. Gene expression analysis in cucumber leaves primed by root colonization with Pseudomonas chlororaphis O6 upon challenge-inoculation with Corynespora cassiicola. Plant Biol. 6:105-108.
Kubicek, C. P., Herrera-Estrella, A., Seidl-Seiboth, V., Martinez, D. A., Druzhinina, I. S., Thon, M., Zeilinger, S., Casas-Flores, S., Horwitz, B. A., Mukherjee, P. K., Mukherjee, M., Kredics, L., Alcaraz, L. D., Aerts, A., Antal, Z., Atanasova, L., Cervantes-Badillo, M. G., Challacombe, J., Chertkov, O., McCluskey, K., Coulpier, F., Deshpande, N., von Dohren, H., Ebbole, D. J., Esquivel-Naranjo, E. U., Fekete, E., Flipphi, M., Glaser, F., Gomez-Rodriguez, E. Y., Gruber, S., Han, C., Henrissat, B., Hermosa, R., Hernandez-Onate, M., Karaffa, L., Kosti, I., Le Crom, S., Lindquist, E., Lucas, S., Lubeck, M., Lubeck, P. S., Margeot, A., Metz, B., Misra, M., Nevalainen, H., Omann, M., Packer, N., Perrone, G., Uresti-Rivera, E. E., Salamov, A., Schmoll, M., Seiboth, B., Shapiro, H., Sukno, S., Tamayo-Ramos, J. A., Tisch, D., Wiest, A., Wilkinson, H. H., Zhang, M., Coutinho, P. M., Kenerley, C. M., Monte, E., Baker, S. E., and Grigoriev, I. V. 2011. Comparative genome sequence analysis underscores mycoparasitism as the ancestral life style of Trichoderma. Genome Biol. 12:R40.

Lardet, L., Aguilar, M., Michaud Ferrière, N., and Berthouly, M. 1998. Effect of strictly plant-related factors on the response of Hevea brasiliensis and Theobroma cacao nodal explants cultured in vitro. In Vitro Cell. Dev. Biol. Plant 34:34-40.

Lardet, L., Dessailly, F., Carron, M. P., Montoro, P., and Monteuuis, O. 2009. Influences of aging and cloning methods on the capacity for somatic embryogenesis of a mature Hevea brasiliensis genotype. Tree Physiol. 29:291-298.

Lardet, L., Martin, F., Dessailly, F., Carron, M. P., and Montoro, P. 2007. Effect of exogenous calcium on post-thaw growth recovery and subsequent plant regeneration of cryopreserved embryogenic calli of Hevea brasiliensis (Müll. Arg.). Plant Cell Rep. 26:559-569.

Lardet, L., Piombo, G., Oriol, F., Dechamp, E., and Carron, M. P. 1999. Relation between biochemical characteristics and conversion ability in Hevea brasiliensis zygotic and somatic embryos. Can. J. Bot. 77: 1168-1177.

Li, E., Jiang, L., Guo, L., Zhang, H., and Che, Y. 2008. Pestalachlorides A-C, antifungal metabolites from the plant endophytic fungus Pestalotiopsis adusta. Bioorg. Med. Chem. 16:7894-7899.

Liu, K., Yang, Y., Miao, C. P., Zheng, Y. K., Chen, J. L., Chen, Y. W., Xu, L. H., Guang, H. L., Ding, Z. T., and Zhao, L. X. 2016a. Koningiopisins A$\mathrm{H}$, polyketides with synergistic antifungal activities from the endophytic fungus Trichoderma koningiopsis. Planta Med. 82:371-376.

Liu, K., Yang, Y. B., Chen, J. L., Miao, C. P., Wang, Q., Zhou, H., Chen, Y. W., Li, Y. Q., Ding, Z. T., and Zhao, L. X. 2016b. Koninginins N-Q, polyketides from the endophytic fungus Trichoderma koningiopsis harbored in Panax notoginseng. Nat. Prod. Bioprospect. 6:49-55.

Lopez, D., Ribeiro, S., Label, P., Fumanal, B., Venisse, J. S., Kohler, A., de Oliveira, R. R., Labutti, K., Lipzen, A., Lail, K., Bauer, D., Ohm, R. A., Barry, K. W., Spatafora, J., Grigoriev, I. V., Martin, F. M., and Pujade-Renaud, V. 2018. Genome-wide analysis of Corynespora cassiicola leaf fall disease putative effectors. Front. Microbiol. 9:276.

Maharachchikumbura, S. S., Hyde, K. D., Groenewald, J. Z., Xu, J., and Crous, P. W. 2014. Pestalotiopsis revisited. Stud. Mycol. 79:121-186.

Mahgoub, E. 1969. Corynespora cassiicola, a new agent of maduromycetoma. J. Trop. Med. Hyg. 72:218-221.

Mathiyazhagan, S., Kavitha, K., Nakkeeran, S., Chandrasekar, G., Manian, K., Renukadevi, P., Krishnamoorthy, A. S., and Fernando, W. G. D. 2004. PGPR-mediated management of stem blight of Phyllanthus amarus (Schum and Thonn) caused by Corynespora cassiicola (Berk and Curt) Wei. Arch. Phytopathol. Plant Prot. 37:183-199.

Montoro, P., Carron, M. P., Granet, F., Lardet, L., Leclercq, J., Dessailly, F., Martin, F., Gaurel, S., Uche, E., Rio, M., and Oliver, G. 2012. Development of new varietal types based on rejuvenation by somatic embryogenesis and propagation by conventional budding or microcutting in Hevea brasiliensis. Acta Hortic. 961:553-576.

Qi, Y.-X., Zhang, X., Pu, J.-J., Liu, X.-M., Lu, Y., Zhang, H., Zhang, H.-Q., Lv, Y.-C., and Xie, Y.-X. 2011. Morphological and molecular analysis of genetic variability within isolates of Corynespora cassiicola from different hosts. Eur. J. Plant Pathol. 130:83-95.

R Core Team. 2015. R: A Language and Environment for Statistical Computing. R Foundation for Statistical Computing, Vienna, Austria.

Reino, J. L., Guerrero, R., Hernández-Galán, R., and Collado, I. 2008. Secondary metabolites from species of the biocontrol agent Trichoderma. Phytochem. Rev. 7:89-123.

Rocha, S. L., Evans, H. C., Jorge, V. L., Cardoso, L. A. O., Pereira, F. S. T., Rocha, F. B., Barreto, R. W., Hart, A. G., and Elliot, S. L. 2017. Recognition of endophytic Trichoderma species by leaf-cutting ants and their potential in a Trojan-horse management strategy. R. Soc. Open Sci. 4: 160628 .

Rodriguez, R. J., White, J. F., Jr., Arnold, A. E., and Redman, R. S. 2009. Fungal endophytes: Diversity and functional roles. New Phytol. 182:314-330.

Samuels, G. J., Dodd, S. L., Lu, B.-S., Petrini, O., Schroers, H.-J., and Druzhinina, I. S. 2006. The Trichoderma koningii aggregate species. Stud. Mycol. 56:67-133. 
Saxena, A., Raghuwanshi, R., and Singh, H. B. 2015. Trichoderma species mediated differential tolerance against biotic stress of phytopathogens in Cicer arietinum L. J. Basic Microbiol. 55:195-206.

Shimomoto, Y., Sato, T., Hojo, H., Morita, Y., Takeuchi, S., Mizumoto, H., Kiba, A., and Hikichi, Y. 2011. Pathogenic and genetic variation among isolates of Corynespora cassiicola in Japan. Plant Pathol. 60:253-260.

Silva, H. S. A., da Silva Romeiro, R., Macagnan, D., de Almeida Halfeld-Vieira, B., Pereira, M. C. B., and Mounteer, A. 2004. Rhizobacterial induction of systemic resistance in tomato plants: Non-specific protection and increase in enzyme activities. Biol. Control 29:288-295.

Sumabat, L., Kemerait, R. C., and Brewer, M. T. 2018. Phylogenetic diversity and host specialization of Corynespora cassiicola responsible for emerging target spot disease of cotton and other crops in the southeastern United States. Phytopathology 108:892-901.

Tejesvi, M. V., Kini, K. R., Prakash, H. S., Subbiah, V., and Shetty, H. S. 2007. Genetic diversity and antifungal activity of species of Pestalotiopsis isolated as endophytes from medicinal plants. Fungal Divers. 24: 37-54.

Tran, D. M., Clément-Demange, A., Déon, M., Garcia, D., Le Guen, V., Clément-Vidal, A., Soumahoro, M., Masson, A., Label, P., Le, M. T., and Pujade-Renaud, V. 2016. Genetic determinism of sensitivity to Corynespora cassiicola exudates in rubber tree (Hevea brasiliensis). PLoS One 11: e0162807.

Vos, C. M., De Cremer, K., Cammue, B. P., and De Coninck, B. 2015. The toolbox of Trichoderma spp. in the biocontrol of Botrytis cinerea disease. Mol. Plant Pathol. 16:400-412.

White, T., Bruns, T., Lee, S., and Taylor, J. 1990. Amplification and direct sequencing of fungal ribosomal RNA genes for phylogenetics. Pages 315-322 in: PCR Protocols: A Guide to Methods and Applications. M. Innis, D. Gelfand, J. Shinsky, and T. White, eds. Academic Press, San Diego, CA, U.S.A.

Wu, J., Xie, X., Shi, Y., Chai, A., Wang, Q., and Li, B. 2018a. Erratum to: Variation of cassiicolin genes among Chinese isolates of Corynespora cassiicola. J. Microbiol. 56:691.

Wu, J., Xie, X., Shi, Y., Chai, A., Wang, Q., and Li, B. 2018b. Variation of cassiicolin genes among Chinese isolates of Corynespora cassiicola. J. Microbiol. 56:634-647.

Xie, Z., Wu, W., Meng, D., Zhang, Q., Ma, Y., Liu, W., and Chen, J. 2018. A case of Phaeohyphomycosis caused by Corynespora cassiicola infection. BMC Infect. Dis. 18:444.

Zachow, C., Berg, C., Muller, H., Monk, J., and Berg, G. 2016. Endemic plants harbour specific Trichoderma communities with an exceptional potential for biocontrol of phytopathogens. J. Biotechnol. 235:162-170. 